\title{
Correction to: Non-market Strategies in International Business
}

\author{
Vikrant Shirodkar, Roger Strange and Steven McGuire
}

\section{Correction to:}

V. Shirodkar et al. (eds.), Non-market Strategies

in International Business, The Academy of International Business, https://doi.org/10.1007/978-3-030-35074-1

The original version of the book was inadvertently published with the following errors: The online abstract of Chapter 2 had errors and the online abstract of Chapter 4 contained the contents of Chapter 5 . These have now been corrected.

The updated versions of these chapters can be found at 